\title{
The effect of Tributyltin on thyroid follicular cells of adult male albino rats and the possible protective role of green tea: a toxicological, histological and biochemical study
}

\author{
Fatma M. M. Badr El Dine ${ }^{1 *}$ Iman M. Nabil ${ }^{2}$ and Fatma I. Dwedar ${ }^{3}$
}

\begin{abstract}
Introduction: Tributyltin is one of the important and wide-spread persistent organic contaminants that accumulate in the food chain. It is suspected to cause endocrine-disrupting effects in mammals, due in part to its possible transfer through marine food chains and to the consumption of contaminated seafood.

Aim of the work: Was to study the possible toxic effect of Tributyltin on thyroid follicular cells of adult male albino rats and to evaluate the possible protective role of green tea.

Material and methods: Forty-five adult male albino rats were included and randomly divided into 3 equal groups: a control group (Group I); Group II: received tributyltin chloride (TBT) dissolved in corn oil orally in a dose of $5 \mathrm{mg} / \mathrm{kg}$ for 30 days. Group III: received tributyltin chloride in the same dose with concomitant oral administration of green tea extract for 30 days. At the end of the experiment, the animals were sacrificed and blood samples were subjected to hormonal assay for T3, T4 and TSH levels. Malondialdehyde and reduced glutathione were assessed. The thyroid tissue was processed for histological and ultrastructure examination. The colloid area of thyroid follicles was evaluated morphometrically and statistically analyzed.

Results: A significant decrease in T3 and T4 levels and serum reduced glutathione in the group II when compared with the other groups. Furthermore, a significant increase in serum Malondialdehyde and TSH levels was recorded in group II treated group by comparison to the other two groups. Histopathological and ultrastructural changes of thyroid gland follicles were detected in tributyltin treated rats; the follicular cells appeared swollen and vacuolated. Epithelial stratification was noticed in some foci with excessive vacuolation of the colloid. Dilated rough endoplasmic reticulum filled with flocculent material and increased number of lysosomes were also detected together with variation in shape and size of the nuclei. A marked improvement in the histological features of thyroid follicles was noticed in group III.
\end{abstract}

Conclusion: Tributyltin induces oxidative stress in rats as well as anti-thyroid effect. The green tea extract is useful in combating tissue injury that is a result of tributyltin toxicity.

Keywords: Tributyltin, Organotin, Green tea extract, Thyroid

\footnotetext{
* Correspondence: fatmabadreldine@yahoo.com

${ }^{1}$ Departments of Forensic Medicine and Clinical Toxicology, Faculty of

Medicine, Alexandria University, Champollion Street, El- Khartoum Square,

Azarita Medical Campus, Alexandria, Egypt

Full list of author information is available at the end of the article
} 


\section{Introduction}

Exposure to endocrine disrupting chemicals grabs more attention nowadays and represents international concern of many national and international health organizations, as well as being a political issue in various countries (Acerini \& Hughes, 2006).

According to the World Health Organization (WHO), an endocrine disruptor is defined as "...an exogenous substance or mixture that modulates function(s) of the endocrine system and consequently causes adverse health effects in an intact organism, or its progeny, or (sub)populations" (Damstra et al., 2002).

Organotin compounds (OT), as tributyltin (TBT) and triphenyltin (TPT), are prevalent contaminants that have been widely used as biocides, agriculture fungicides and wood preservatives. Furthermore, they have been utilized as disinfecting agents in circulating industrial cooling waters, as well as, antifouling paints for marine vessels (Antizar-Ladislao, 2008).

Even though the usage of Tributyltins has been banned since 2008, they continue to persist in the environment, leading to severe contamination of the ecosystems as well as its accumulation in biological tissues (Horiguchi, 2012).

TBT at relatively high concentrations as hundreds of nanomoles has been found in human blood (AntizarLadislao, 2008) and the lipophilicity of organotin compounds favors their toxicity at membrane level, as well as disrupting diverse biological processes, involved in the endocrine, (Sharan et al., 2013) the immune, (Brown \& Whalen, 2015) and nervous systems (Dong et al., 2006).

Moreover, TBT are reported to be a perilous factor for cardiovascular disease impairing the coronary vascular reactivity to estradiol, (dos Santos et al., 2012) as well as, altering aorta morphology and functionality (Rodrigues et al., 2014).

Accumulating data suggests that TBT can act as an endocrine disruptor. TBT has been known to produce imposex (a superimposition of male features in females) in marine gastropods through inhibition of aromatase enzyme that converts androgen to estrogen (Sousa et al., 2009; Lima et al., 2011). In mammals, nanomolar concentrations of tributyltin disturbed steroidogenesis (Yamazaki et al., 2005). Organotin compounds as endocrine disruptors are indicated as a possible cause of congenital hypothyroidism (Adeeko et al., 2003).

Recently, Tributyltin toxicity is considered as a precipitating factor for transgenerational obesity by disturbing the levels of key hormones linked to energy homeostasis (Nicole, 2013; Chamorro-García et al., 2013).

TBT has also been reported to be an environmental risk factor for Parkinson's disease, by inhibiting dopamine biosynthesis and enhancing L-DOPA-induced cytotoxicity (Kim et al., 2007).
Thyroid hormones are of crucial importance for the normal function of nearly every organ, as they are involved in normal brain development, control of metabolism, and many other substantial aspects of normal adult physiology. Therefore, adverse effects may impact development, metabolism, or adult physiology if there are changes in the function of the thyroid gland or intervention with the ability of thyroid hormone to exert its action (Brent, 2012). However, the mechanism(s) by which TBT induces toxicity have not been fully established.

Some researchers reported that the organotin can induce oxidative damage to mice cells both in vivo and in vitro (Liu et al., 2008). Oxidative stress, which results from the overproduction of reactive oxygen species (ROS), causes cellular oxidative injury such as lipid peroxidation, protein oxidation, and DNA damage (Ishihara et al., 2012).

Green tea, a popular well-known beverage worldwide, has captured considerable attention for its scientifically beneficial effects on human health. Most of its significant effects are attributed to its polyphenolic flavonoids, known as catechins (epicatechin, epigallocatechin, epicatechin-3gallate, as well as the major flavonoid (-)-epigallocatechin-3-gallate). The most pervasive recognized properties of green tea are their antioxidant activities, arising from their ability to scavenge reactive oxygen species (Rietveld \& Wiseman, 2003; Clement, 2009).

Taken the above-mentioned considerations, the present study is conducted specifically, to investigate the probable toxic effect of Tributyltin chloride on thyroid follicular cells of adult male albino rats, and the possible impact of reactive oxygen species (ROS) on the normal function of the thyroid gland, revealing its relation to TBT toxicity. Meanwhile, to assess whether the green tea extract in low dose, simultaneously given with TBT, exerts some protective effects on the thyroid tissues.

\section{Material and methods Chemicals}

Tributyltin chloride and corn oil were purchased from Sigma-Aldrich Chemical Company, St. Louis, MO, USA. Purity of TBT was $96 \%$.

Green tea extract (GTE) was supplied in the form of tablets (200 mg) obtained from the Technomed Groups Company, Egypt; then dissolved in distilled water.

\section{Animals and experimental design}

Forty-five specifically pathogen free adult male albino rats (weighting 200-230 g) were included in the present work. All procedures followed the guidelines for the care and handling of animals and the study protocol was approved by the ethical committee of Alexandria Faculty of Medicine.

The animals were housed under the same laboratory conditions of light and temperature with free access to 
standard laboratory food and water. They were acclimatized to the new circumstances for one week prior to the start of the experiment. The duration of the experiment was 30 days.

The rats were randomly assigned to three numerically equal experimental groups (15 animals each) as follows:

Group I (the control group): which was further, divided into 3 equal subgroups, (5 rats each):

- Group Ia:

Each rat in this group received $3 \mathrm{ml}$ of distilled water orally via orogastric-tube.

- Group Ib: Each rat in this group received $0.4 \mathrm{ml}$ of corn oil orally via orogastric-tube.

- Group Ic: Rats of this group received green tea extract of $150 \mathrm{mg} / \mathrm{kg}$. body weight dissolved in $3 \mathrm{ml}$ of distilled water orally via orogastric-tube (Hamdy et al., 2012).

Group II (Tributyltin-treated group): each rat in this group received Tributyltin chloride dissolved in corn oil in a dose of $5 \mathrm{mg} / \mathrm{kg}$ for 30 days (Mitra et al., 2014).

Group III (TBT + GTE group): received Tributyltin chloride dissolved in corn oil in a dose of $5 \mathrm{mg} / \mathrm{kg}$ with concomitant administration of green tea extract (150 mg/kg body weight) for 30 days (Hamdy et al., 2012).

\section{Methods}

\section{Hormonal analysis}

Determination of serum T3, T4 and TSH At the end of the experimental period (30 days), blood samples were collected from rats' carotid arteries. Centrifugation was done at $400 \mathrm{x} \mathrm{g}$ (times gravity) for $5 \mathrm{~min}$ and serum was kept at $-20{ }^{\circ} \mathrm{C}$ for further analysis of triiodothyronine (T3), thyroxine (T4) and thyroid stimulating hormone (TSH) levels by ELISA (Kuriyama et al., 2007).

\section{Antioxidant enzymes and lipid peroxidation}

For determination of markers of oxidative stress, blood samples were collected, without using any anticoagulant and then the blood was allowed to clot for $30 \mathrm{~min}$ at $25{ }^{\circ} \mathrm{C}$. The blood was centrifuged at $700 \mathrm{x}$ g for $10 \mathrm{~min}$. A pipette was used to separate the top yellow serum layer without disturbing the white Buffy layer.

\section{Estimation of reduced glutathione (GSH)}

Reduced glutathione (GSH) content was assayed by the method reported by Miwa et al., (Miwa et al., 1989) GSH determination is based on the development of a yellow color when $5,5^{\prime}$ dithiobis (2-nitro benzoic acid) (DTNB) is added to compounds containing sulfhydryl groups. The values are expressed as $\mathrm{mg} / \mathrm{dL}$.

\section{Determination of Maliondialdehyde (MDA)}

The serum was added to $8.1 \%$ sodium dodecyl sulphate (SDS), 20\% acetic acid solution adjusted to PH 3.5, and $0.8 \%$ thiobarbituricacid (TBA). Distilled water was added to the mixture to make a solution of $4 \mathrm{ml}$, and then subjected to heating in a water bath at $95{ }^{\circ} \mathrm{C}$ for $1 \mathrm{~h}$. After cooling, $1 \mathrm{ml}$ distilled water and $5 \mathrm{ml}$ of $\mathrm{n}$-butanolpyridine $(15: 1 ; v / v)$ mixture were added. The absorbance of the organic layer was measured at $532 \mathrm{~nm}$. A standard curve was constructed using different concentrations of 1, 1, 3, 3- Tetra methoxypropane in ethanol. The concentration of MDA in sample was determined in $\mathrm{nmol} / \mathrm{ml}$ (Ohkawa et al., 1979).

\section{Histological study}

All the rats were sacrificed by decapitation under light ether anesthesia. The thyroid glands were immediately removed from animals at the time of sacrifice, and the tissues were processed for light and electron microscopic examination.

- Light microscopic study

One lobe of the thyroid gland was fixed in 10\% of neutral buffered formalin, dehydrated and embedded in paraffin. Then the 5- $\mu$ m-thickness paraffin sections were cut and stained with hematoxylin and eosin (H\&E) stains (Bancroft \& Gamble, 2008).

- Electron microscopic study Specimens for electron microscopic examination were immediately fixed in $2.5 \%$ glutaraldehyde buffered with $0.1 \mathrm{M}$ phosphate buffer at $\mathrm{pH} 7.4$ and then post-fixed in $1 \%$ osmium tetroxide in the same buffer. They were dehydrated and then embedded in epoxy resin. Ultrathin sections were cut, double stained with uranyl acetate and lead citrate and examined with a JEOL 100 CX electron microscope (JEOL, Tokyo, Japan) at Electron Microscopic Unit, Faculty of Science, Alexandria University (Hayat, 2000).

- Histomorphometric study:

The colloid area of 10 randomly selected thyroid follicles were measured from the H\&E-stained sections of the thyroid gland of each animal per group at magnification of 100 using the Image Analyzer (Olympus BX41TF, Tokyo, Japan) at the Cell Biology Department, Medical Research Institute, Alexandria University. Such data were subjected to bio statistical analysis.

\section{Statistical analysis}

Analysis of data was done using IBM SPSS software package version 20 and the following were calculated: Range (minimum and maximum), mean and standard deviations. For normally distributed data, comparison between the three studied groups was analyzed using F-test (ANOVA) 
and Post Hoc test (LSD). p-value less than 0.05 was considered statistically significant.

\section{Results}

\section{Biochemical results}

In the present work, no statistical difference was found among the three subgroups of the control group. A significant decrease in the levels of T3 and T4 has been recorded after 30 days of TBT administration when compared with both the control and the TBT+ GTE groups (Tables 1 and 2). On the contrary, the serum level of TSH was significantly increased in the TBT treated group (Table 3). In addition, the level of serum GSH was decreased in the TBT treated group (Tables 4). Table 5 demonstrates a significant increase in serum MDA level in the TBT treated group when compared with the other two groups.

\section{Histological results}

\section{Histomorphometric study:}

The mean colloid area of the thyroid follicles was significantly lowered in TBT treated group relative to the control group. On the other hand, the mean colloid area of the third group did not show any significant change when compared with the control group (Table 6).

\section{Light microscopic results:}

\section{Group I (control group):}

Light microscopic examination of sections of thyroid gland showed; multiple follicles filled with acidophilic homogenous colloid. The lining follicular cells were flattened to cuboidal in shape with oval to rounded pale nuclei Fig. 1.

\section{Group II (Tributyltin treated group):}

Examination of sections of thyroid gland of TBT-treated rat revealed markedly vacuolated colloid. Most of the follicular cells appeared swollen and vacuolated. Other cells showed loss of their nuclei. Congested blood capillaries were also observed. Figure $2 \mathrm{a} \& \mathrm{~b}$ Stratification of the epithelial lining was encountered in some follicles. Small sized follicles were also depicted. Figure 2b More disruption in the architecture of the glands was noticed, manifested by empty fused follicles lined by flattened cells with dark flattened nuclei Fig. 3.

\section{Group III (TBT+ GTE group):}

Light microscopic examination of sections of thyroid gland of this group revealed; preservation of the architecture of the gland. Moderately vacuolated homogenous acidophilic colloid filling the lumina of the follicles. The lining cells showed normal appearance of the nucleus and the cytoplasm. On the other hand, few vacuolated cells were still encountered Fig. 4.

\section{Electron microscopic results: \\ Group I (control group):}

Ultrastructural examination of thyroid follicular cells of the control group (Group I) showed a flattened to cuboidal cell with a microvillous border and an oval to rounded euchromatic nucleus. The cytoplasm revealed mitochondria, rough endoplasmic reticulum and lysosomes. An intact tight junction was also encountered Fig. 5a \& b.

\section{Group II (Tributyltin-treated group)}

Electron microscopic examination of thyroid follicular cells of TBT-treated rats (Group II) revealed cuboidal to high columnar cells Fig. 6. Short, blunt and disrupted microvilli were depicted in some cells Fig. 7. The nuclei of some cells were normal in shape and euchromatic while other cells showed changes varied from small irregular and dark nuclei Figs. 7 and 9 to dilatation of perinuclear cisterna Fig. 8a. The cytoplasm showed mild to markedly dilated rough endoplasmic reticulum Figs. 6, 7, 8 and 9. The lumina of some of them were filled with flocculent material Fig. 8a \& b. Mitochondria with disrupted cristae were also encountered Figs. 6 and $8 \mathrm{~b}$. Numerous vesicles and lysosomes were also noticed Figs. 7 and 9. Some of the follicular cells were arranged in layers Fig. 9.

Table 1 Serum level of T3 in the TBT-treated group compared with the control and the TBT + GTE groups

\begin{tabular}{lllll}
\hline T3 $(\mathrm{ng} / \mathrm{dl})$ & Control group $(n=15)$ & TBT treated group $(n=15)$ & TBT + GTE group $(n=15)$ & $\mathrm{F}$ \\
\hline Min. - Max. & $79.0-108.0$ & $39.0-49.0$ & $53.0-60.0$ & $351.426^{*}$ \\
Mean \pm SD. & $93.13 \pm 8.22$ & $43.13 \pm 3.40$ & $57.20 \pm 2.46$ & $<001^{*}$ \\
Median & 92.0 & 42.0 & 57.0 & \\
Significance between groups & $\mathrm{p}_{1}<0.001^{*}, \mathrm{p}_{2}<0.001^{*}, \mathrm{p}_{3}<0.001^{*}$ & & \\
\hline
\end{tabular}

F: $F$ test (ANOVA), Significance between groups was done using Post Hoc Test (LSD) $\mathrm{p}_{1}: p$ value for comparing between Control and TBT treated groups $\mathrm{p}_{2}: p$ value for comparing between Control and TBT + GTE groups $\mathrm{p}_{3}: p$ value for comparing between TBT treated and TBT + GTE groups

*: Statistically significant at $p \leq 0.05$ 
Table 2 Serum level of T4 in the TBT-treated group compared with the control and the TBT + GTE groups

\begin{tabular}{lllll}
\hline T4 $(\mu \mathrm{g} / \mathrm{dl})$ & Control group $(n=15)$ & TBT treated group $(n=15)$ & TBT + GTE group $(n=15)$ & $\mathrm{F}$ \\
\hline Min. - Max. & $4.30-5.50$ & $1.20-2.30$ & $1.99-2.40$ & $385.726^{*}$ \\
Mean \pm SD. & $4.80 \pm 0.43$ & $1.57 \pm 0.38$ & $2.16 \pm 0.15$ & $<0.001^{*}$ \\
Median & 4.80 & 1.50 & 2.20 & \\
Significance between groups & $\mathrm{p}_{1}<0.001^{*}, \mathrm{p}_{2}<0.001^{*}, \mathrm{p}_{3}<0.001^{*}$ & & \\
\hline
\end{tabular}

F: F test (ANOVA), Significance between groups was done using Post Hoc Test (LSD)

$\mathrm{p}_{1}: p$ value for comparing between Control and TBT treated groups

$\mathrm{p}_{2}: p$ value for comparing between Control and TBT + GTE groups

$\mathrm{p}_{3}: p$ value for comparing between TBT treated and TBT + GTE groups

*: Statistically significant at $p \leq 0.05$

\section{Group III (TBT + GTE group)}

Ultrastructural examination of thyroid follicular cells of this group that received TBT + GTE (Group III) showed marked improvement of most of the examined follicular cells. They were cuboidal in shape and exhibited a welldeveloped microvillous border. Their nuclei were euchromatic and rounded. The cytoplasm showed normal profiles of rough endoplasmic reticulum Fig. 10a. Although mildly dilated rough endoplasmic reticulum and multiple lysosomes were still encountered in some cells Fig. 10b.

\section{Discussion}

Over the last decades, a dramatic increase in hormonal disorders was reported, and it has been assumed that growing exposure to endocrine disrupting chemicals (EDCs) contributes to the burden of endocrine disorders among populations. However, a deluge of research in the field of endocrine disruption has focused on estrogenicity (Sikka \& Wang, 2008; Roy et al., 2009).

At present, there are scanty reports on the impact of TBT on thyroid tissues. Thereby, this spurred us to conduct an oral toxicity study to provide further inclusive information pertaining to the effect of Tributyltin on the thyroid follicular cells.

Thyroid hormone homeostasis appears to be the target of plentiful environmental chemicals either natural or manufactured. In mammals, thyroid glandular activity is commonly determined by thyroid hormone secretion rate (Zoeller, 2007). Taking into consideration that the structure of any organ closely reflects the state of its function; histological examination of the thyroid gland provides a sensitive early indicator of the glandular activity than serum T3 and T4 levels.

In this context, the primary aim of the present study was to assess the alteration in thyroid homeostasis that might occur following exposure to Tributyltin. Furthermore, this study aimed to identify potential associations between TBT and reactive oxygen species (ROS) on the normal function of the thyroid gland and the probable protective role of green tea extract when given simultaneously with TBT.

The dosing regimen and the duration selected in the current study was in accordance with the work of (Mitra et al., 2014) who studied the sub chronic toxicity of TBT in rats. He reported that one month exposure to TBT in low doses resulted in loss of cell viability in liver, kidney as well as the lungs.

The male rats were selected in the current study, as increasing evidence elucidates that estrogen influence the risk of thyroid diseases. It also plays a crucial role as a promoting factor in thyroid tumorigenesis (Derwahl \& Nicula, 2014).

In the present study, the rats treated with Tributyltin demonstrated significant decrease in the serum levels of T3 and T4 along with the evident increase in TSH levels as compared with the control group. Similar disruption of the levels of these hormones were reported by previous researchers (Adeeko et al., 2003; Wang et al., 2008; Sharan et al., 2014) who attributed its occurrence to the antithyroid effect of TBT.

Table 3 Serum level of TSH in the TBT-treated group compared with the control and the TBT + GTE groups

\begin{tabular}{lllll}
\hline TSH $(\mu \mathrm{lU} / \mathrm{ml})$ & Control group $(n=15)$ & TBT treated group $(n=15)$ & TBT + GTE group $(n=15)$ & $\mathrm{F}$ \\
\hline Min. - Max. & $0.11-0.39$ & $2.58-3.18$ & $0.18-2.73$ & $130.483^{*}$ \\
Mean \pm SD. & $0.28 \pm 0.09$ & $2.81 \pm 0.20$ & $1.65 \pm 0.71$ & $<001^{*}$ \\
Median & 0.31 & 2.77 & 1.76 & \\
Significance between groups & $\mathrm{p}_{1}<0.001^{*}, \mathrm{p}_{2}<0.001^{*}, \mathrm{p}_{3}<0.001^{*}$ & & \\
\hline
\end{tabular}

F: $F$ test (ANOVA), Significance between groups was done using Post Hoc Test (LSD)

$\mathrm{p}_{1}: p$ value for comparing between Control and TBT treated groups

$\mathrm{p}_{2}: p$ value for comparing between Control and TBT + GTE groups

$\mathrm{p}_{3}: p$ value for comparing between TBT treated and TBT + GTEgroups

*: Statistically significant at $p \leq 0.05$ 
Table 4 Comparison between the studied groups according to the level of reduced glutathione

\begin{tabular}{|c|c|c|c|c|c|}
\hline Reduced glutathione (mg/dl) & Control group $(n=15)$ & TBT treated group $(n=15)$ & TBT + GTE group $(n=15)$ & $\mathrm{F}$ & $p$ \\
\hline Min. - Max. & $1.32-1.61$ & $1.09-1.21$ & $1.11-1.23$ & $142.538^{*}$ & $<0.001^{*}$ \\
\hline Mean \pm SD. & $1.46 \pm 0.08$ & $1.14 \pm 0.04$ & $1.19 \pm 0.04$ & & \\
\hline Median & 1.47 & 1.12 & 1.20 & & \\
\hline Significance between groups & \multicolumn{5}{|c|}{$p_{1}<0.001^{*}, p_{2}<0.001^{*}, p_{3}=0.023^{*}$} \\
\hline
\end{tabular}

F: F test (ANOVA), Significance between groups was done using Post Hoc Test (LSD)

$\mathrm{p}_{1}: p$ value for comparing between Control and TBT treated groups

$\mathrm{p}_{2}: p$ value for comparing between Control and TBT + GTE groups

$\mathrm{p}_{3}: p$ value for comparing between TBT treated and TBT + GTEgroups

*: Statistically significant at $p \leq 0.05$

This was further asserted by histological examination of follicular cells, which unveiled evident structural changes, reflecting augmented activity in thyroid follicles of this group, in response to hypersecretion of TSH to compensate the decreasing levels of T3 and T4. These changes were manifested by swollen vacuolated follicular cells, epithelial stratification, along with excessive vacuolation of the colloid. Congested blood vessels were also encountered. These changes were further bolstered by morphometric and statistical analyses that revealed a significant decrease in the mean colloid area of thyroid follicles as compared with their respective controls.

In accordance with our results, (Pereira et al., 2013) reported disorganization of follicular cell groups, with hypertrophy, hyperplasia of thyrocytes and glandular congestion compared with control thyroid gland. On the other hand, he found no changes in plasma levels of $\mathrm{T}_{3}$ and $\mathrm{T}_{4}$ after 15 days of treatment in his study. This could be clarified by the shorter duration of his research when compared with the present one.

It is acknowledged that prolonged stimulation of the pituitary by decreasing levels of thyroid hormones results in release of elevated levels of TSH by the thyrotrophs which may lead to thyroid gland neoplasia manifested as shrinkage of colloid area, hypertrophy as well as hyperplasia of follicular cells (Hood et al., 1999; Boelaert, 2009). Moreover, the present study demonstrated small sized follicles, empty and fused follicles accompanied by disturbance of the normal architecture of the gland. Similar findings were reported by (Wang et al., 2008) while studying the effect of TBT on thyroid gland of Xenopus laevis. They stated that TBT can induce intense damage to the thyroid tissues. This damage manifested by reduction in follicular region, colloid depletion and malformed follicles.

Ultra-structurally, the follicular cells revealed mild to moderately dilated rough endoplasmic reticulum. Mitochondria with disrupted cristae were also encountered together with ample lysosomes and vesicles. Some follicular cells showed cuboidal to high columnar cells. Meanwhile, some of the nuclei appeared small and shrunken with peripheral clumping of heterochromatin, while other nuclei showed dilated perinuclear cisternae.

Our results are consistent with those of (Sharan et al., 2014) who studied the effect of TBT on thyroid gland, they declared that TBT possessed antithyroid effect via intervention with thyroid hormone regulation. Such disturbance occurred through decreasing the transcription of thyroid hormone receptors (TR) by disrupting the physiological concentrations of thyroid hormones, thereby increasing the ligand-dependent cooperativity of TR with the co-repressors and shedding of the co-activator. Additionally, TBT caused down-regulation of the thyroid peroxidase and thyroglobulin genes, which correlated with the decrease in T3 and T4, while boosting the thyroid stimulating hormone (TSH) levels. Furthermore, Tributyltin can cause up-regulation of thyroid-stimulating hormone receptor in the thyroid glands.

However, it is quite apparently that thyroid gland activity is positively regulated by thyroid stimulating

Table 5 Comparison between the studied groups according to the level of MDA

\begin{tabular}{lllll}
\hline MDA $(\mathrm{nmol} / \mathrm{ml})$ & Control group $(n=15)$ & TBT treated group $(n=15)$ & TBT + GTE group $(n=15)$ & $\mathrm{F}$ \\
\hline Min. - Max. & $11.60-37.80$ & $50.30-65.20$ & $40.40-50.40$ & $98.915^{*}$ \\
Mean \pm SD. & $29.81 \pm 7.19$ & $57.57 \pm 5.28$ & $46.20 \pm 3.02$ & $<.001^{*}$ \\
Median & 32.70 & 55.70 & 47.10 & \\
Significance between groups & $\mathrm{p}_{1}<0.001^{*}, \mathrm{p}_{2}<0.001^{*}, \mathrm{p}_{3}<0.001^{*}$ & & \\
\hline
\end{tabular}

F: F test (ANOVA), Significance between groups was done using Post Hoc Test (LSD)

$\mathrm{p}_{1}: p$ value for comparing between Control and TBT treated groups

$\mathrm{p}_{2}: p$ value for comparing between Control and TBT + GTEgroups

$\mathrm{p}_{3}: p$ value for comparing between TBT treated and TBT + GTEgroups

* Statistically significant at $p \leq 0.05$ 
Table 6 Comparison between the different studied groups according to colloid area of thyroid follicles in pixels

\begin{tabular}{llll}
\hline Area $\times 10^{3}$ & Control group $(n=15)$ & TBT treated group $(n=15)$ & TBT + GTE group $(n=15)$ \\
\hline Min. - Max. & $13.5-160.9$ & $7.1-24.3$ & $6.06-160.7$ \\
Mean \pm SD. & $80.1 \pm 50.2$ & $15.4 \pm 4.3$ & $73 \pm 49.8$ \\
Median & 80.5 & 15.1 & 72.3 \\
Significance between groups & $\mathrm{p}_{1}=0.012^{*}, \mathrm{p}_{2}=0.8430, \mathrm{p}_{3}=.023^{*}$. & \\
\hline
\end{tabular}

Significance between groups was done using Post Hoc Test (LSD)

$\mathrm{p}_{1}: p$ value for comparing between Control and TBT treated groups

$\mathrm{p}_{2}: p$ value for comparing between Control and TBT + GTE groups

$\mathrm{p}_{3}: p$ value for comparing between TBT treated and TBT + GTE groups

*: Statistically significant at $p \leq 0.05$

hormone (TSH) synthesized and secreted from pituitary thyrotrophs, whose activity is in turn controlled by the hypothalamic TSH-releasing hormone (TRH). TSH acts on specific receptors on the membrane of follicular cells and invigorates the activity of the sodium-iodine symporter and of intracellular enzymes involved in thyroid hormone synthesis.

Therefore, when the level of serum thyroid hormone dwindles, the feedback inhibition of TSH is attenuated and more TSH is secreted; this promotes thyroid cell hyperplasia and hypertrophy and stirs the function of the thyroid into the active state to sustain the body thyroid hormone needed (Chiamolera \& Wondisford, 2009).

In the context, (Scanlan et al., 2004) have speculated that increased lysosomal activity in the follicular cells, is simply a reflection of augmented cellular secretory activity initiated by high levels of circulating TSH. It could also be triggered by enhanced phagocytosis secondary to the degenerative changes noticed in some cells.

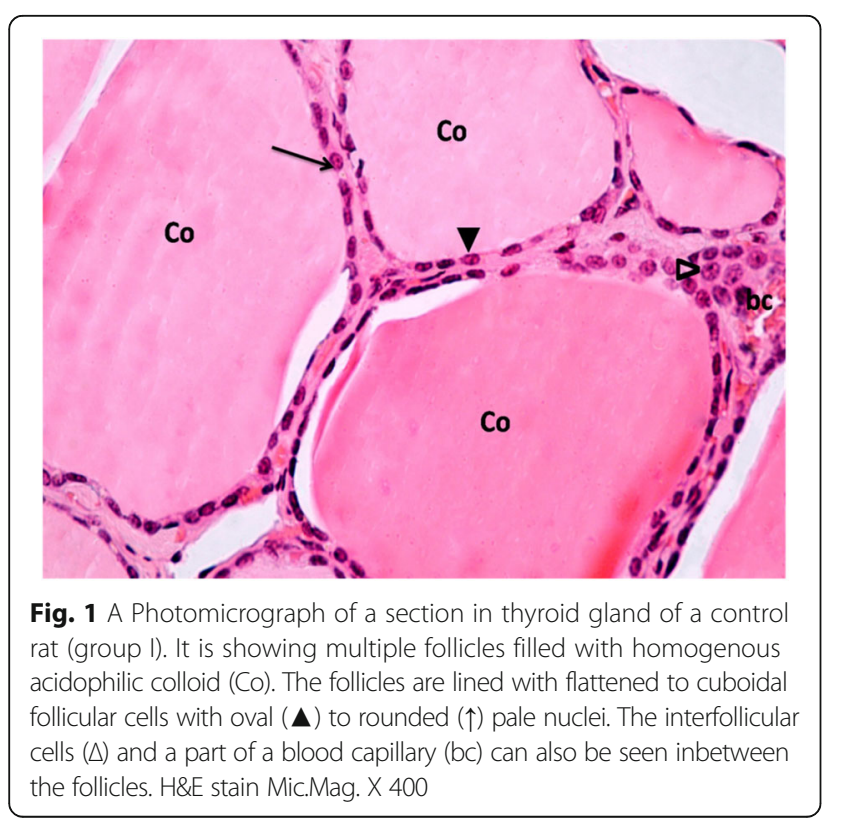

Myriads of reports (Patrick, 2009; Jugan et al., 2010) suggest that thyroid disruptors can target the thyroid endocrine cascade at various levels encompassing several molecular components of the hypothalamus-pituitarythyroid-periphery (HPTP) axis as well as the functioning of the peripheral tissues including; iodine uptake, thyroid hormone production, interconversion of thyroid hormones, cellular uptake and cell receptor activation.

Thyroid follicles represent the functional subunit of thyroid tissue. Each follicle is lined by a single epithelial cell layer and is filled with a thyroglobulin (TG) containing colloidal mass formed in the rER and serving as the matrix for thyroid hormone (TH) synthesis.

In addition, TG also plays an imperative role in modulating the expression of genes involved in the synthesis of other thyroid proteins (sodium-iodide symporter [NIS] and thyroid peroxidase [TPO]) and transcription factors involved in normal thyroid physiology (Sellitti et al., 2001).

Glycosylation of TG begins in the rough endoplasmic reticulum (rER) and is completed in the Golgi complex. Within thyroid follicles, newly synthesized TG is transported along the secretory route to the apical plasma membrane of thyroid epithelial cells. After exocytosis, TG is stored within the extracellular lumen of thyroid follicles in a covalently cross-linked form (van de Graaf et al., 2001).

Because TH are iodothyronine derivatives, uptake of iodide from the blood stream represents a substantial step in their biosynthesis. During the process of generating $\mathrm{TH}$, tyrosine residues on the TG molecule are coupled with iodine at the apical pole of thyrocyte. This iodination process is called organification and is controlled by the enzyme thyroid peroxidase (TPO). Thus, monoiodotyrosine (MIT) and diiodotyrosine (DIT) are formed. The coupling of MIT and DIT is also mediated by TPO as well as linking two DIT molecules to form $\mathrm{T} 4$. In addition to thyroglobulin and iodide, TPO requires $\mathrm{H}_{2} \mathrm{O}_{2}$ as a third factor to carry out the above-mentioned reactions. $\mathrm{H}_{2} \mathrm{O}_{2}$ production is presumably a rate-limiting step during $\mathrm{TH}$ generation (Song et al., 2007). 


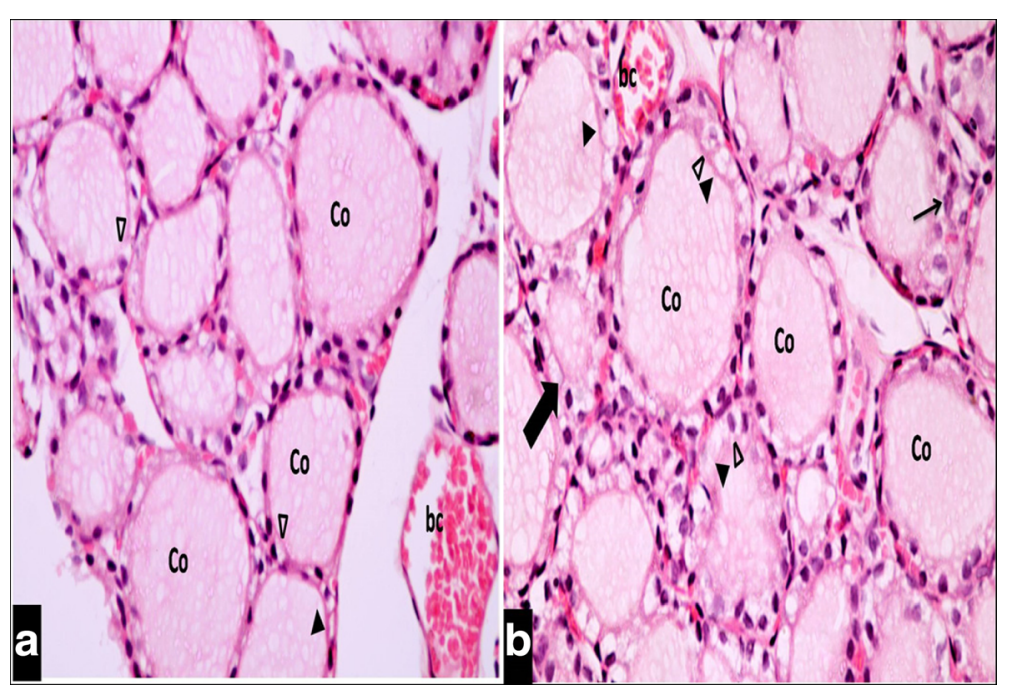

Fig. 2 a \& b: A Photomicrograph of a section in thyroid gland of a TBT-treated rat (group II). It reveals extensive vacuolated colloid (Co) filling the follicular lumen. Most of the follicular cells appear swollen and vacuolated $(\Delta)$, while others show loss of their nuclei $(\boldsymbol{\Delta})$. The other follicle is lined by multiple layers of follicular cells ( $\uparrow$ ). A small follicle with narrow lumen (thick $\uparrow$ ) can also be seen. A nearby congested blood capillary (bc) is observed. H\&E stain. Mic.Mag. X 400

At the thyrocyte level, stimulation of the TSH receptor (TSHR) by TSH instigates several second messenger signaling cascades leading to increased iodide uptake, TH synthesis and secretion (Roger et al., 2010; Vassart \& Costagliola, 2011).

It is well known that the morpho functional status of each follicle is controlled not solely by the TSH level, but rather by other factors including thyroglobulin contained within the follicle (Suzuki et al., 2011).

Thyroid hormone liberation begins with endocytosis of small amounts of colloid into vesicles that are transported inside the follicular cells. Lysosomes then fuse

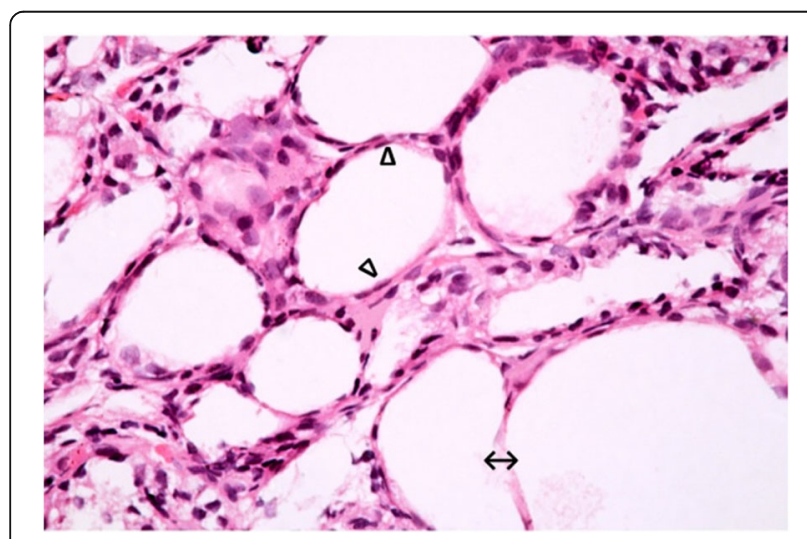

Fig. 3 A Photomicrograph of a section in thyroid gland of a TBT-treated rat (group II). It is showing disruption of the normal architecture of the gland. The follicular lumina are empty. Some of the follicles are fused $(\leftrightarrow)$. Most of the follicular cells appear flattened with dark flattened nuclei $(\Delta)$. H\&E stain. Mic.Mag. X 400 with these vesicles and release T4/T3. Each TG molecule stores ten times more T4 than T3 (Scanlan et al., 2004).

Although the damage of follicular cells in the thyroid seems to be a reason for impaired thyroid hormones, yet a prospective role of oxidative stress might be another reason.

The further step of the study was to evaluate the susceptibility of reactive oxygen species (ROS) to contribute in the modulation of thyroid structure.

Under normal physiological conditions, reductive power of a cell is achieved by the amount of reduced glutathione. It helps to attain oxidative damage under

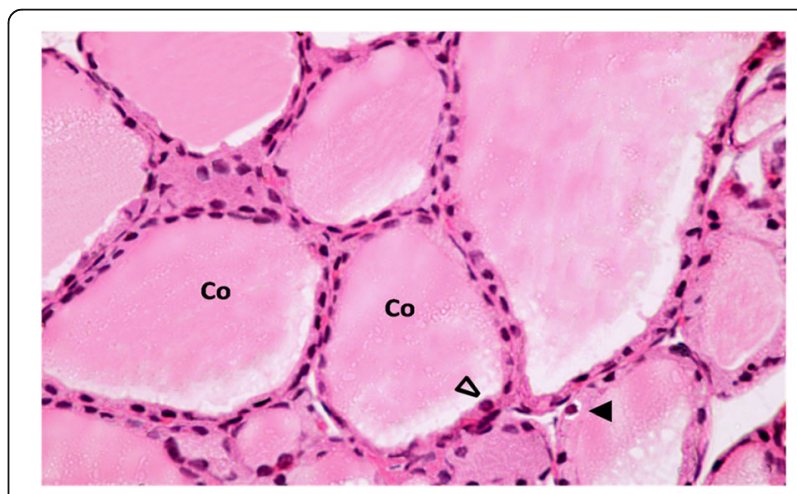

Fig. 4 A Photomicrograph of a section in thyroid gland of a TBT-treated rat that received green tea (group III). It is showing moderately vacuolated colloid (Co) filling the follicular lumen. Most of the follicular cells appear with oval to rounded nuclei $(\Delta)$ and normal cytoplasm, while others still reveal mild vacuolated cytoplasm ( $\mathbf{\Delta})$. H\&E stain Mic.Mag. X 400 


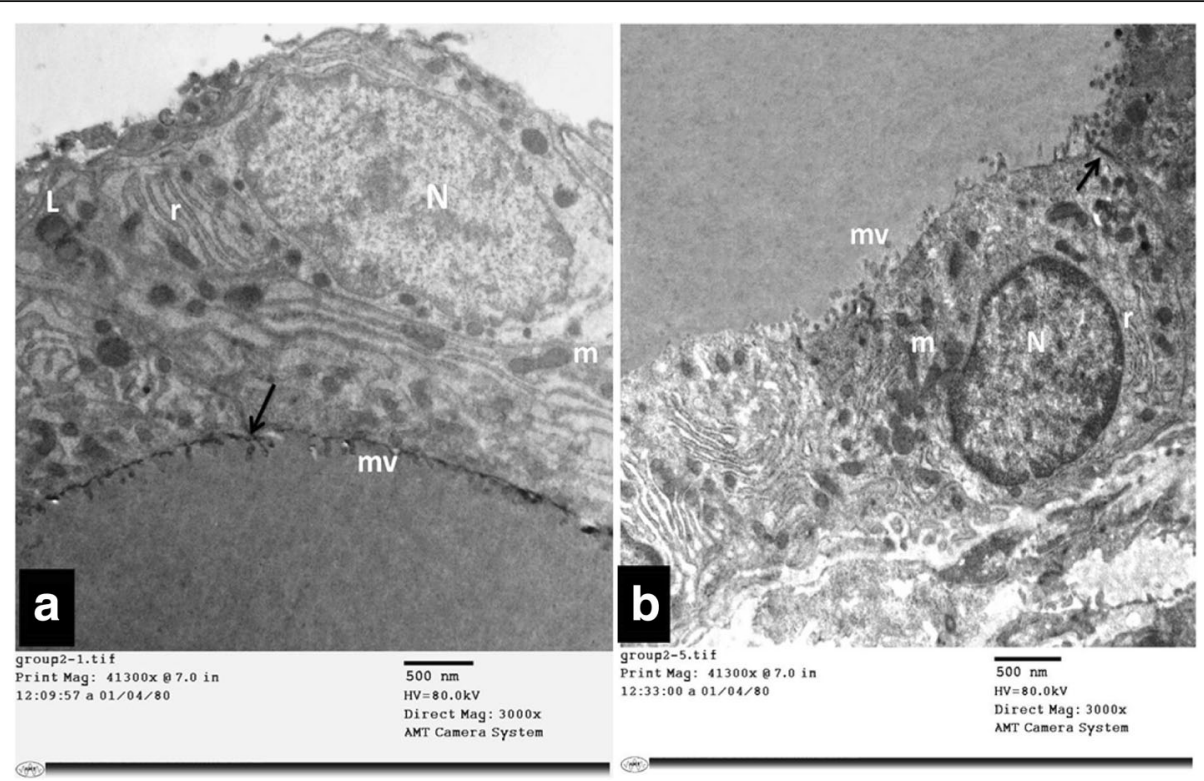

Fig. 5 a \& b: Electron micrographs of thyroid follicular cells of control rat (Group I). It is showing flattened to cuboidal cells with oval to rounded euchromatic nucleus ( $\mathrm{N}$ ) and microvillous border (mv). The cytoplasm reveals parallel arrays of rough endoplasmic reticulum $(\mathrm{r})$, mitochondria $(\mathrm{m})$ and lysosomes (L). An intact tight junction $(\uparrow)$ is also noticed

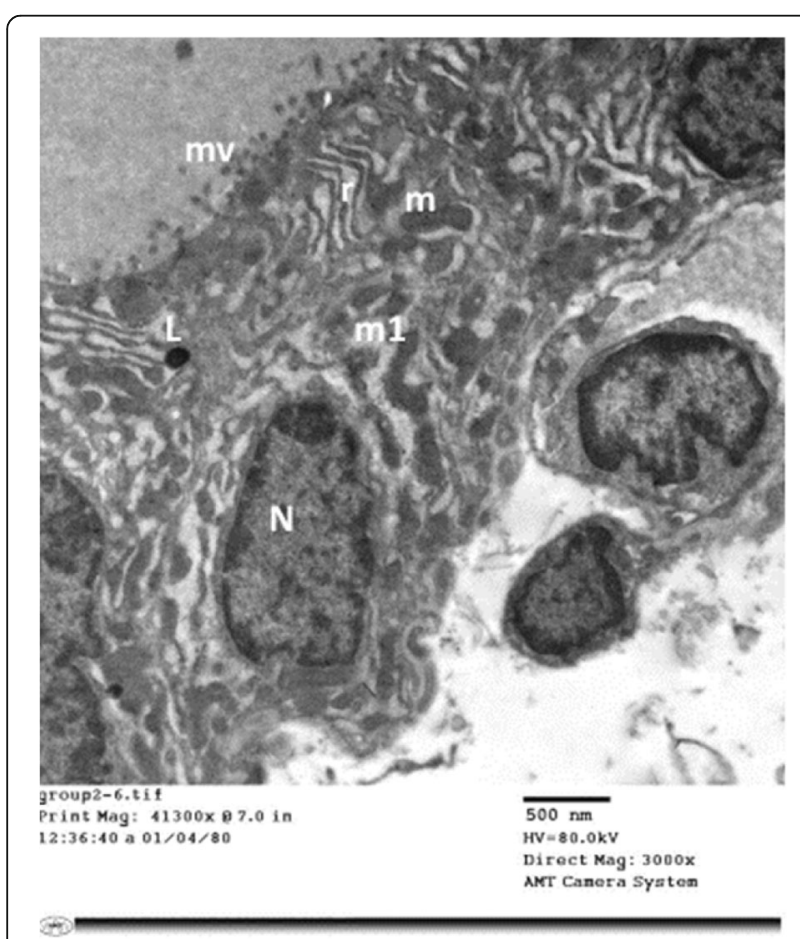

Fig. 6 An electron micrograph of thyroid follicular cells of TBT-treated rat (Group II). It is showing high columnar cells with oval nuclei (N). The cytoplasm reveals multiple dilated profiles of rough endoplasmic reticulum (r). Some of the mitochondria appear normal $(\mathrm{m})$ while other exhibit disrupted cristae (m1). Notice: (mv); microvilli, (L); Lysosomes

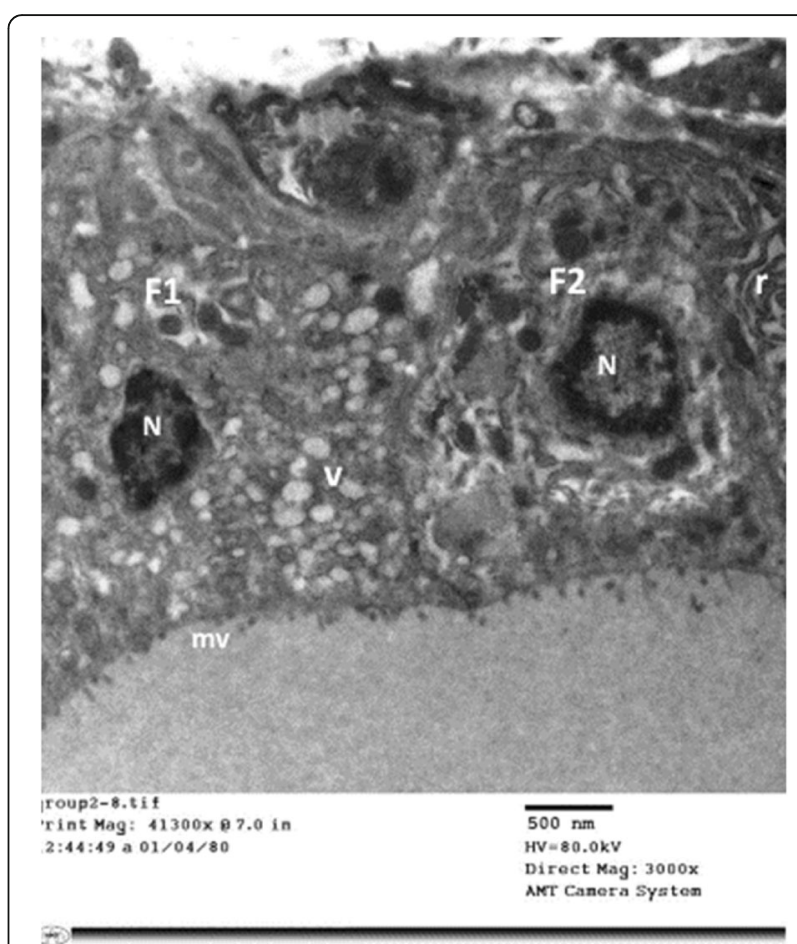

Fig. 7 An electron micrograph of thyroid follicular cells of TBT-treated rat (Group II). It is showing two cuboidal cells (F1\&F2). The microvilli $(\mathrm{mv})$ are short and blunt. The nuclei $(\mathrm{N})$ are small and irregular with peripheral clumping of heterochromatin. F1 cell exhibits numerous vesicles (V). F2 cell depicts dilated profiles of rough endoplasmic reticulum ( $r)$ 


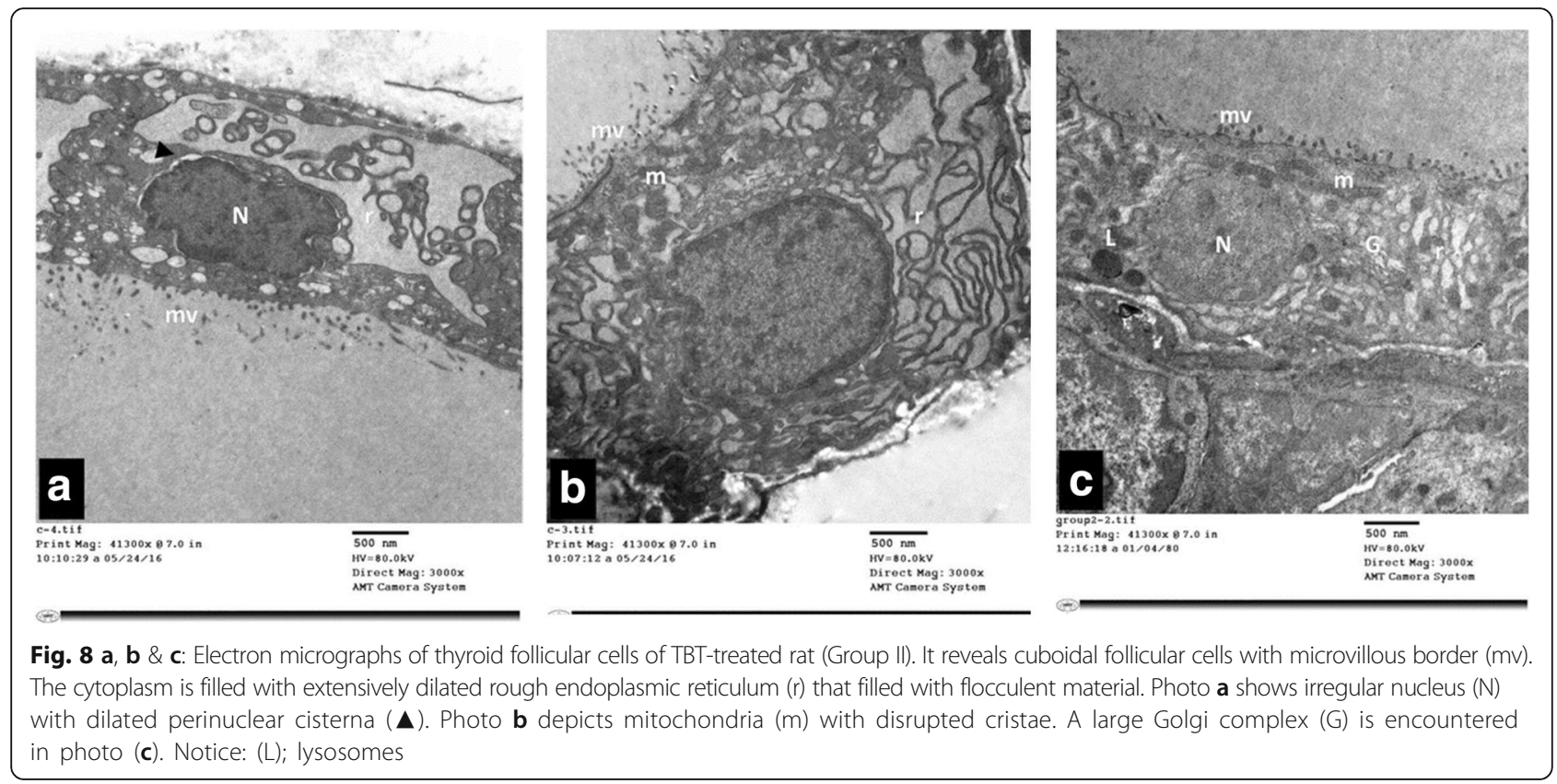

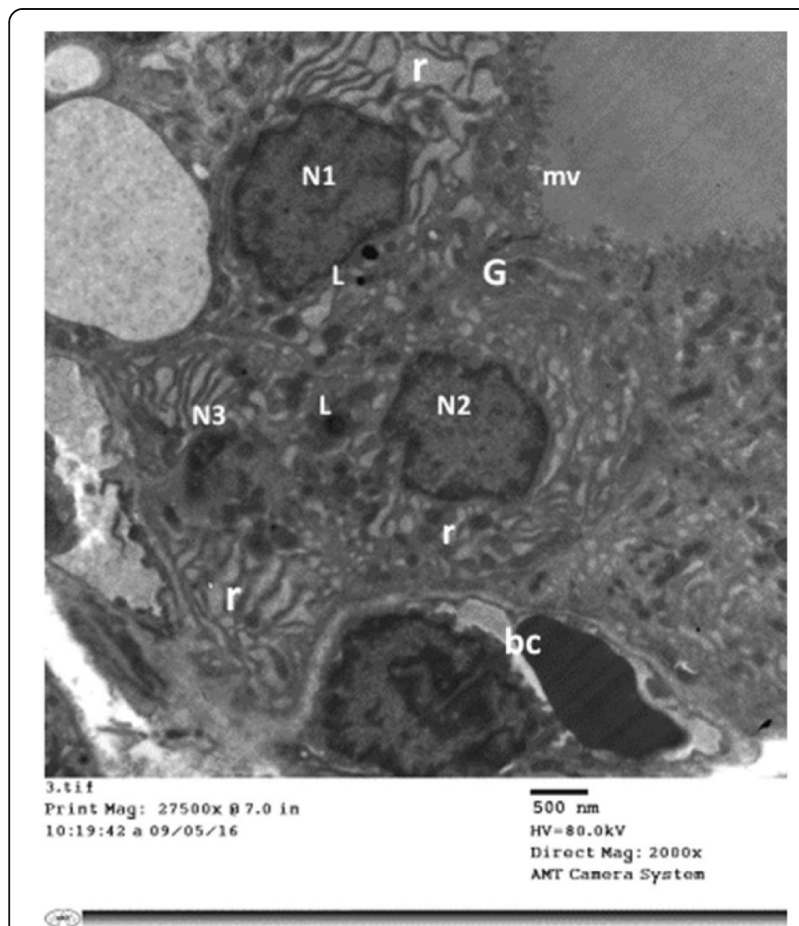

Fig. 9 An electron micrograph of thyroid follicular cells of TBT-treated rat (Group II). It is showing follicular cells arranged in layers. The nuclei (N1\&N2) are euchromatic, while N3 is small and heterochromatic. The cytoplasm reveals dilated rough endoplasmic reticulum ( $r$ ) and multiple lysosomes (L). Notice: (G); Golgi apparatus, (mv); microvilli, (bc); blood capillaries control by various processes and reduction in GSH leads to stress (Lushchak, 2012).

Malondialdehyde (MDA) is one of the major oxidation products of peroxidized polyunsaturated fatty acids, and thus increased MDA content is an imperative indicator of lipid peroxidation (Rahal et al., 2014).

The results of the present study depicted significant decrease in the level of serum GSH, as well as an increase in the level of serum MDA levels in the TBT treated group in relation to the other groups.

In concomitant with the previous results, ROS generation may be a radical factor underlying TBT toxicity. Multitude of studies (Demir et al., 2011; Mitra et al., 2013; Zhang et al., 2014; Bernat et al., 2014) have suggested that the generation of ROS, including the species derived from $\mathrm{H}_{2} \mathrm{O}_{2}$ such as $\mathrm{OH}$, is one of the mechanisms involved in TBT toxicity. ROS cause damage to mitochondrial and other cytoplasmic organelle membrane structures through peroxidation of phospholipids, proteins and nucleotides. Consequently, membrane stability and integrity being disrupted resulting in osmolality changes and hydropic cell degeneration (Guo et al., 2013). Meanwhile, lipid peroxidation activates endonuclease enzymes, with subsequent breakdown of nuclear DNA and nuclear degeneration (Zhang et al., 2016).

On the other hand, (Mitra et al., 2014) reported that; reactive oxygen species but not lipid peroxidation content was observed to be significantly elevated both in the tissues and serum after a month of low dose of TBT exposure.

Similarly, (Gupta et al., 2011) on his research on thymus; clarified that oxidative stress and apoptosis are two inseparable phenomena in TBT toxicity. 


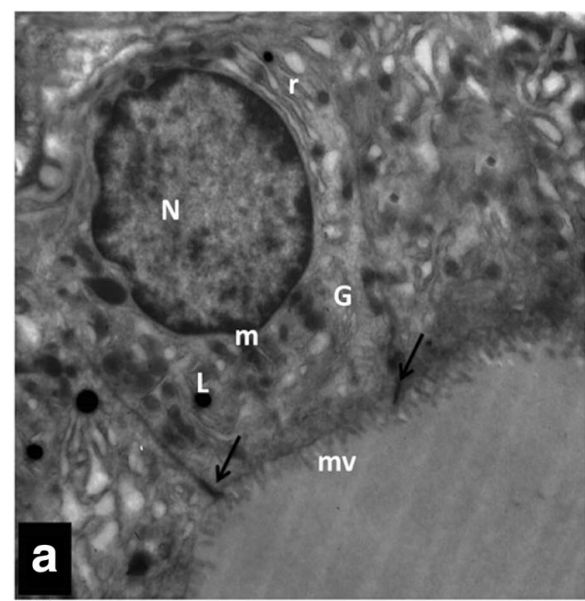

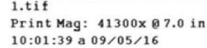

$\overline{\substack{500 \mathrm{~nm} \\ \mathrm{HV}=80.0 \mathrm{kV}}}$

HV $=80.0 \mathrm{kV}$
Diroct Mag: $3000 \mathrm{x}$
Wh C

AMT Camera Systen

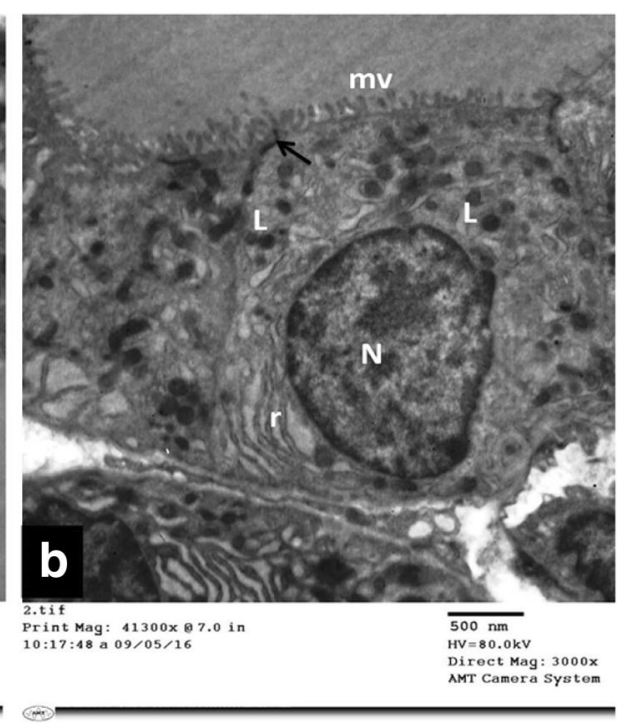

Fig. 10 a \& b: Electron micrographs of thyroid follicular cells of TBT + GTE group (Group III). It is showing cuboidal cells with a well-developed microvillous (mv) border. The nucleus $(\mathrm{N})$ is euchromatic and rounded. The cytoplasm shows normal to mildly dilated rough endoplasmic reticulum ( $\mathrm{r}$ ), lysosomes (L), mitochondria (m) and Golgi apparatus (G). An intact tight junction ( $\uparrow$ ) is also noticed

As a recap, it is obvious that oxidative stress as the final manifestation of a multi-step pathway, refers to cellular status imbalance between the ROS level and the cellular antioxidant defense system due to the depletion of antioxidants, or the excessive accumulation of ROS, or both, which leads to cellular damage. It has been demonstrated that exposure to TBT could yield ROS which cause various organ lesions. Approximately 0.1\% of all oxygen entering the mitochondrial electron transport chain is released as ROS, which can disrupt intracellular redox status and result in homeostasis disorder (Zhang et al., 2008; Zhou et al., 2010).

Based upon the work done by (Li et al., 2015) a significant elevation of the oxidative stress indices was observed following TBT exposure, which suggested that oxidative stress was induced by TBT. Upon amalgamating previous results with the findings of this study, it is deduced that oxidative damage is one of the critical toxic mechanism of TBT.

Furthermore, (Sugawara et al., 2002) stated that reactive oxygen species can also inactivate thyroid peroxidase enzyme via two mechanisms, reversible formation of compound III due to excessive $\mathrm{H}_{2} \mathrm{O}_{2}$ or $\mathrm{O}_{2}^{-}$, and irreversible free radical-mediated thyroid peroxidase (TPO) inactivation through attacking the active site of thyroid peroxidase enzyme, causing inactivation of the catalytic site of this enzyme resulting in disruption of the level of thyroid hormones.

In the current work, co administration of green tea extract (GTE) with TBT for 30 days resulted in considerable thyroid preservation. Few cells still showed mildly dilated rER and numerous lysosomes. These histological effects correlated as well with the morphometric and biochemical results that showed significant amelioration of these attributes.

These data were on a par with (Liu et al., 2008) who reported that green tea polyphenols (GTPP) were effective in reducing TBT-induced oxidative damage both in vivo and in vitro. They found that (ROS) production and malondialdehyde content of the liver in mice exposed to TBT were dwindled in the GTPP-treated group compared to the untreated group. Moreover, they demonstrated that the number of cells with damaged DNA in untreated mice was figured out to be significantly higher compared to GTPP-treated mice. Furthermore, damage to the nuclei and mitochondria observed in TBT-treated mice were alleviated in mice treated with both TBT and GTPP. They attributed this protective role to the powerful ability of GTPP to scavenge ROS and hinder DNA breaks.

Several studies (Narotzki et al., 2012; Giménez et al., 2013) reported that green GTE constitutes an essential source of antioxidants. Besides polyphenols, GTE contains additional antioxidants such as carotenoids, tocopherols (vitamin E derivatives) and vitamin C. Tea contains further minerals that function as co-factors in antioxidant enzymes: zinc, selenium and manganese. Polyphenols have supplementary mechanisms in which they reduce oxidation level besides direct role as antioxidants.

As antioxidants, green tea polyphenols either chelate redox-active metal ions, such as iron and copper preventing the formation of metal-catalyzed free radicals or scavenge reactive oxygen/nitrogen species or modulate antioxidant enzymes (Nakagawa \& Yokozawa, 2002). 
On the contrary, prior researches (Chandra et al., 2011; Abulfadle et al., 2015) have declared that excessive and high doses of green tea have the potential to alter the thyroid gland physiology and architecture, that is, enlargement of thyroid gland as well as hypertrophy and/or hyperplasia of the thyroid follicles and inhibition of the activity of thyroid peroxidase and 50-deiodinase I with elevated thyroidal sodium-potassium- ATPase activity along with significant decrease in serum T3 and $\mathrm{T} 4$, and a parallel increase in serum thyroid stimulating hormone (TSH).

\section{Conclusion}

Thus, the current study provides novel information that accentuate the hazardous risk of TBT on the thyroid. Co-administration of green tea extract (natural antioxidant) improves Tributyltin induced morphological changes in thyroid architecture as well as restoration of glutathione activity.

The available toxicity data might provide a useful platform for further studies to clarify the human risk and to boost the global awareness about endocrine-disrupting chemicals.

These issues highlight the critical need to develop swift and robust tools to identify TBT compounds, as they are deeply interwoven with our daily lives from various sources. Thus, a holistic and comprehensive understanding of the mechanisms underlying thyroid disruption, may lead to changes in public policy and awareness, and make it possible to limit adverse outcomes for future generations.

\section{Abbreviations}

DIT: Diiodotyrosine; EDCs: Endocrine disrupting chemicals; GSH: Estimation of Reduced Glutathione; GTE: Green tea extract; GTPP: Green tea polyphenols; H\&E: Hematoxylin and eosin; HPTP: Hypothalamus-pituitary-thyroid-periphery; MDA: Maliondialdehyde; MIT: Monoiodotyrosine; NIS: Sodium-iodide symporter; OT: Organotin; rER: Rough endoplasmic reticulum; ROS: Reactive oxygen species; T3: Triiodothyronine; T4: Thyroxine; TBT: Tributyltin; TG: Thyroglobulin; TPO: Thyroid peroxidase; TPT: Triphenyltin; TR: Thyroid hormone receptors; TRH: TSH-releasing hormone; TSH: Thyroid stimulating hormone; TSHR: TSH receptor; WHO: World Health Organization

\section{Acknowledgements}

None.

\section{Funding}

None.

\section{Authors' contributions}

FBED Associate Professor of Forensic Medicine\& Clinical Toxicology, Faculty of Medicine, Alexandria University, Alexandria, Egypt. Responsible of the toxicological design of the research, starting from the idea, gathering the data, references and writing the paper. IN Lecturer of Histology and cell biology, Faculty of Medicine, Alexandria University, Alexandria, Egypt. Responsible in writing the paper in addition to the histological analysis (Light microscopic and electron microscopic analysis of the specimens). FD Lecturer of Medical Biochemistry, Faculty of Medicine, Alexandria University, Alexandria, Egypt. Responsible of the biochemical analysis of the samples collected. All authors read and approved the final manuscript.
Ethics approval and consent to participate

All procedures followed the guidelines for the care and handling of animals and the study protocol was approved by the ethical committee of Alexandria Faculty of Medicine.

\section{Competing interests}

The authors declared that they have no competing interests.

\section{Publisher's Note}

Springer Nature remains neutral with regard to jurisdictional claims in published maps and institutional affiliations.

\section{Author details \\ ${ }^{1}$ Departments of Forensic Medicine and Clinical Toxicology, Faculty of Medicine, Alexandria University, Champollion Street, El- Khartoum Square, Azarita Medical Campus, Alexandria, Egypt. ${ }^{2}$ Histology and cell biology, Faculty of Medicine, Alexandria University, Alexandria, Egypt. ${ }^{3}$ Medical Biochemistry, Faculty of Medicine, Alexandria University, Alexandria, Egypt.}

Received: 26 May 2017 Accepted: 26 June 2017

Published online: 18 July 2017

\section{References}

Abulfadle KA, Bakhaat GA, Shaik R, Tantry BA (2015) Effect of excessive green tea versus fluoride and caffeine on body weight and serum thyroid hormones in male mice. J Phys Pharm Adv 5(2):565-573

Acerini CL, Hughes IA (2006) Endocrine disrupting chemicals: a new and emerging public health problem? Arch Dis Child 91:633-638

Adeeko A, Li D, Forsyth DS, Casey V, Cooke GM, Barthelemy J, Cyr DG, Trasler JM, Robaire B, Hales BF (2003) Effects of in Utero Tributyltin chloride exposure in the rat on pregnancy outcome. Toxicol Sci 74:407-415

Antizar-Ladislao B (2008) Environmental levels, toxicity and human exposure totributyltin (TBT)-contaminated marine environment. Environ Int 34:292-308

Bancroft JD, Gamble M (eds) (2008). The hematoxylin and eosin. In: Theory \& practice of histological techniques. 6th edn. Churchill Livingstone Elsevier, Philadelphia, pp 121-35

Bernat P, Gajewska E, Szewczyk R, Słaba M, Długoński J (2014) Tributyltin (TBT) induces oxidative stress and modifies lipid profile in the filamentous fungus Cunninghamella Elegans. Environ Sci Pollut Res 21(6):4228-4235

Boelaert K (2009) The association between serum TSH concentration and thyroid cancer. Endocr Relat Cancer 16(4):1065-1072

Brent GA (2012) Mechanisms of thyroid hormone action. J Clin Invest 122(9): 3035-3043

Brown S, Whalen M (2015) Tributyltin alters secretion of interleukin 1 Beta from human immune cells. J Appl Toxicol 35(8):895-908

Chamorro-García R, Sahu M, Abbey RJ, Laude J, Pham N, Blumberg B (2013) Transgenerational inheritance of increased fat depot size, stem cell reprogramming, and hepatic steatosis elicited by prenatal exposure to the obesogen tributyltin in mice. Environ Health Perspect 121(3):359-366

Chandra AK, De N, Choudhury SR (2011) Effect of different doses of unfractionated green and black tea extracts on thyroid physiology. Hum Exp Toxicol 30(8):884-896

Chiamolera MI, Wondisford FE (2009) Minireview: thyrotropin-releasing hormone and the thyroid hormone feedback mechanism. Endocrinology 150:10911096

Clement Y (2009) Can green tea do that? A literature review of the clinical evidence. Prev Med 49(2-3):83-87

Damstra T, Barlow S, Bergman A, Kavlock R, Van Der Kraak G (2002). Global assessment of the state-of-the-science of endocrine disruptors. Geneva: The International Programme on Chemical Safety (IPCS), World Health Organization

Demir F, Uzun FG, Durak D, Kalender Y (2011) Subacute chlorpyrifos-induced oxidative stress in rat erythrocytes and the protective effects of catechin and quercetin. Pestic Biochem Physiol 99(1):77-81

Derwahl M, Nicula D (2014) Estrogen and its role in thyroid cancer. Endocr Relat Cancer 21(5):T 273-T 283

Dong W, Muramoto W, Nagai Y, Takehana K, Stegeman JJ, Teraoka H, Hiraga T (2006) Retinal neuronal cell is a toxicological target of tributyltin in developing zebrafish. J Vet Med Sci 68(6):573-579 
Giménez B, López de Lacey A, Pérez-Santín E, López-Caballero ME, Montero P (2013) Release of active compounds from agar and agar-gelatin films with green tea extract. Food Hydrocoll 30(1):264-271

van de Graaf SA, Ris-Stalpers C, Pauws E, Mendive FM, Targovnik HM, de Vijlder JJ (2001) Up to date with human thyroglobulin. J Endocrinol 170(2):307-321

Guo C, Sun L, Chen X, Zhang D (2013) Oxidative stress, mitochondrial damage and neurodegenerative diseases. Neural Regen Res 8(21):2003-2014

Gupta M, Dwivedi UN, Khandelwal S (2011) C-Phycocyanin: an effective protective agent against thymic atrophy by tributyltin. Toxicol Lett 204(1):2-11

Hamdy MA, El-Maraghy SA, Kortam MA (2012) Modulatory effects of curcumin and green tea extract against experimentally induced pulmonary fibrosis: a comparison with N-acetyl cysteine. J Biochem Mol Toxicol 26:461-468

Hayat MA (ed) (2000). Chemical fixation. In: Principles and techniques of electron microscopy: biological applications. 4th edn. Cambridge University Press, UK, pp. 4-85

Hood A, Liu YP, Gattone VH 2nd, Klaassen CD (1999) Sensitivity of thyroid gland growth to thyroid stimulating hormone (TSH) in rats treated with antithyroid drugs. Toxicol Sci 49(2):263-271

Horiguchi T (2012) Ecotoxicological impact of organotins: an overview. In: Pagliarani A, Trombetti F, Ventrella V (eds) Biochemical and biological effects of Organotins. Bentham Science, Italy, pp 3-24

Ishihara Y, Kawami T, Ishida A, Yamazaki T (2012) Tributyltin induces oxidative stress and neuronal injury by inhibiting glutathione S-transferase in rat organotypic hippocampal slice cultures. Neurochem Int 60(8):782-790

Jugan ML, Levi Y, Blondeau JP (2010) Endocrine disruptors and thyroid hormone physiology. Biochem Pharmacol 79(7):939-947

Kim YM, Lee JJ, Park SK, Lim SC, Hwang BY, Lee CK, Lee MK (2007) Effects of tributyltin acetate on dopamine biosynthesis and L-DOPA-induced cytotoxicity in PC12 cells. Arch Pharm Res 30(7):858-865

Kuriyama SN, Wanner A, Fidalgo-Neto AA, Talsness CE, Koerner W, Chahoud I (2007) Developmental exposure to low-dose PBDE-99: tissue distribution and thyroid hormone levels. Toxicology 242(1-3):80-90

Li ZH, Li P, Shi ZC (2015) Chronic exposure to Tributyltin induces brain functional damage in juvenile common carp (Cyprinus carpio). PLoS One 10(4):1-13

Lima D, Reis-Henriques MA, Silva R, Santos Al, Castro LF, Santos MM (2011) Tributyltin-induced imposex in marine gastropods involves tissue-specific modulation of the retinoid $X$ receptor. Aquat Toxicol 101(1):221-227

Liu H, Guo Z, Xu L, Hsu S (2008) Protective effect of green tea polyphenols on tributyltin-induced oxidative damage detected by in vivo and in vitro models. Environ Toxicol 23(1):77-83

Lushchak VI (2012) Glutathione homeostasis and functions: potential targets for Medical interventions. J Amino Acids 2012:1-26

Mitra S, Srivastava A, Khandelwal S (2013) Tributyltin chloride induced testicular toxicity by JNK an p38activation, redox imbalance and cell death in sertoligerm cell co-culture. Toxicology 314(1):39-50

Mitra S, Gera R, Singh V, Khandelwal S (2014) Comparative toxicity of low dose tributyltin chloride on serum, liver, lung and kidney following subchronic exposure. Food Chem Toxicol 64:335-343

Miwa S, Luzzatto L, Rosa R, Raglia DE, Schroter W, De Flora A, Fujii H, Board PG, Beutler E (1989) Recommended methods for an additional red cell enzyme (pyrimidine5'-nucleotidase) assay and the determination of red cell adenosine 5'- triphosphate,2,3-diphosphoglycerate and reduced glutathione. Clin Lab Haematol 11:131-136

Nakagawa T, Yokozawa T (2002) Direct scavenging of nitric oxide and superoxide by green tea. Food Chem Toxicol 40(12):1745-1750

Narotzki B, Reznick AZ, Aizenbud D, Levy Y (2012) Green tea: a promising natural product in oral health. Arch Oral Biol 57(5):429-435

Nicole W (2013) An Obesogen over time: Transgenerational impact of Tributyltin. Environ Health Perspect 121(3):a96

Ohkawa H, Ohishi N, Yagi K (1979) Assay for lipid peroxides in animal tissues by thiobarbituric acid reaction. Anal Biochem 95(2):351-358

Patrick $L$ (2009) Thyroid disruption: mechanism and clinical implications in human health. Altern Med Rev 14(4):326-346

Pereira PR, de Mattos RM, Palmero CY, Fortunato R, Gracelli JB, de Carvalho DP, Nasciutti LE, Miranda-Alves L (2013) Tributyltin changes the thyroid gland morphology of male rats. Endocr Abstr 32:499

Rahal A, Kumar A, Singh V, Yadav B, Tiwari R, Chakraborty S, Dhama K (2014) Oxidative stress, Prooxidants, and antioxidants: the interplay. Biomed Res Int 2014:1-19

Rietveld A, Wiseman S (2003) Antioxidant effects of tea: evidence from human clinical trials. J Nutr 133(10):3285S-3292S

Rodriques SM, Ximenes CF, de Batista PR, Simões FV, Coser PH, Sena GC, Podratz PL, de Souza LN, Vassallo DV, Graceli JB, Stefanon I (2014) Tributyltin contributes in reducing the vascular reactivity to phenylephrine in isolated aortic rings from female rats. Toxicol Lett 225(3):378-385

Roger PP, van Staveren WC, Coulonval K, Dumont JE, Maenhaut C (2010) Signal transduction in the human thyrocyte and its perversion in thyroid tumors. Mol Cell Endocrinol 321(1):3-19

Roy JR, Chakraborty S, Chakraborty TR (2009) Estrogen-like endocrine disrupting chemicals affecting puberty in humans-a review. Med Sci Monit 15(6): RA137-RA145

dos Santos RL, Podratz PL, Sena GC, Filho VS, Lopes PF, Gonçalves WL, Alves LM, Samoto VY, Takiya CM, Miguel ED, Moysés MR, Graceli JB (2012) Tributyltin impairs the coronary vasodilation induced by $17 \beta$-estradiol in isolated rat heart. J Toxic Environ Health A 75(16-17):948-959

Scanlan TS, Suchland KL, Hart ME, Chiellini G, Huang Y, Kruzich PJ, Frascarelli S, Crossley DA, Bunzow JR, Ronca-Testoni S, Lin ET, Hatton D, Zucchi R, Grandy DK (2004) 3-lodothyronamine is an endogenous and rapid-acting derivative of thyroid hormone. Nat Med 10:638-642

Sellitti DF, Suzuki K, Doi SQ, La Granha C, Machado M, Matos T, Kohn LD (2001) Thyroglobulin increases cell proliferation and suppresses Pax-8 in mesangial cells. Biochem Biophys Res Commun 285:795-799

Sharan S, Nikhil K, Roy P (2013) Effects of low dose treatment of tributyltin on the regulation of estrogen receptor functions in MCF-7 cells. Toxicol Appl Pharmacol 269(2):176-186

Sharan S, Nikhil K, Roy P (2014) Disruption of thyroid hormone functions by low dose exposure of tributyltin: an in vitro and in vivo approach. Gen Comp Endocrinol 206:155-165

Sikka SC, Wang R (2008) Endocrine disruptors and estrogenic effects on male reproductive axis. Asian J Androl 10(1):134-145

Song Y, Driessens N, Costa M, De Deken X, Detours V, Corvilain B, Maenhaut C, Miot F, Van Sande J, Many MC, Dumont JE (2007) Roles of hydrogen peroxide in thyroid physiology and disease. J Clin Endocrinol Metab 92(10): 3764-3773

Sousa A, Laranjeiro F, Takahashi S, Tanabe S, Barroso CM (2009) Imposex and organotin prevalence in a European post-legislative scenario: temporal trends from 2003 to 2008. Chemosphere 77:566-573

Sugawara M, Sugawara Y, Wen K, Giulivi C (2002) Generation of oxygen free radicals in thyroi60. Cells and inhibition of thyroid peroxidase. Exp Biol Med 227:141-146

Suzuki K, Kawashima A, Yoshihara A, Akama T, Sue M, Akio Yoshida A, Kimura HJ (2011) Role of thyroglobulin on negative feedback autoregulation of thyroid follicular function and growth. J Endocrinol 209(2):169-174

Vassart G, Costagliola S (2011) G protein-coupled receptors: mutations and endocrine diseases. Nat Rev Endocrinol 7(6):362-372

Wang L, Liu QP, Guo SZ, Qian LJ, Shi HH (2008) Effects of tributyltin on thyroid histology of Xenopus laevis. J East China Norm Univ (Nat Sci) 6:75-81

Yamazaki T, Shimodaira M, Kuwahara $H$, Wakatsuki $H$, Horiuchi $H$, Matsuda $H$, Kominami S (2005) Tributyltin disturbs bovine adrenal steroidogenesis by two modes of action. Steroids 70(14):913-921

Zhang J, Zuo Z, Chen R, Chen Y, Wang C (2008) Tributyltin exposure causes brain damage in Sebastiscus marmoratus. Chemosphere 73:337-343

Zhang Y, Chen Y, Sun L, Liang J, Guo Z, Xu L (2014) Protein phosphatases 2A as well as reactive oxygen species involved in tributyltin induced apoptosis in mouse livers. Environ Toxicol 29(2):234-242

Zhang J, Wang X, Vikash V, Ye Q, Wu D, Liu Y, Dong W (2016) ROS and ROSmediated cellular Signaling. Oxidative Med Cell Longev 2016:1-18

Zhou J, Zhu XS, Cai ZH (2010) Tributyltin toxicity in abalone (Haliotis Diversicolor Supertexta) assessed by antioxidant enzyme activity, metabolic response, and histopathology. J Hazard Mater 183(1-3):428-433

Zoeller RT (2007) Environmental chemicals impacting the thyroid: targets and consequences. Thyroid 17(9):811-817 